\title{
REVIEW
}

\section{Coronary heart disease in individuals with spinal cord injury: assessment of risk factors}

\author{
WA Bauman ${ }^{1,2,3,4}$ and AM Spungen ${ }^{1,2,3,4}$ \\ ${ }^{1}$ Veterans Affairs Rehabilitation Research and Development Center of Excellence for the Medical Consequences of Spinal Cord Injury, \\ Veterans Affairs Medical Center, Bronx, NY, USA; ${ }^{2}$ Medical, Spinal Cord Injury and Research Services, Veterans Affairs Medical \\ Center, Bronx, NY, USA; ${ }^{3}$ Department of Medicine, Mount Sinai Medical Center, New York, NY, USA and ${ }^{4}$ Department of \\ Rehabilitation Medicine, Mount Sinai Medical Center, New York, NY, USA
}

\begin{abstract}
Study design: Discussion document.
Objectives/methods: To review the work performed on conditions and disorders that predispose persons with spinal cord injury ( $\mathrm{SCl}$ ) to an increased risk of coronary heart disease (CHD).

Results/discussion: Individuals with $\mathrm{SCl}$ have an increased prevalence of abnormalities in carbohydrate and lipid metabolism because of immobilization, muscle atrophy and relative adiposity. In those with $\mathrm{SCl}$, an inverse relationship has been reported between serum high-density lipoprotein (HDL) cholesterol values and abdominal circumference, and a direct relationship between serum triglycerides levels and abdominal circumference. Persons with SCI have lower serum HDL cholesterol levels than able-bodied controls. A higher prevalence of insulin resistance and diabetes mellitus, as well as an earlier occurrence of coronary heart disease (CHD), has been reported in persons with $\mathrm{SCl}$ than in the general population. Recently, a higher prevalence and greater degree of coronary artery calcification by electron beam computerized tomography has been demonstrated in persons with $\mathrm{SCl}$, even if matched with the able-bodied population for age, gender, ethnicity and conventional risk factors for CHD. Knowledge of relative risk of $\mathrm{CHD}$ in persons with $\mathrm{SCl}$ is important for appropriate intervention strategies. The conventional risk factors for CHD were determined in veterans with $\mathrm{SCI}$ to assign risk to determine target low-density lipoprotein cholesterol levels for therapeutic intervention. Limitations of conventional guidelines when applied to the $\mathrm{SCl}$ population should be appreciated. Conventional risk factors for CHD should be identified and treated in individuals with $\mathrm{SCl}$, according to current standards of care.
\end{abstract}

Spinal Cord (2008) 46, 466-476; doi:10.1038/sj.sc.3102161; published online 8 January 2008

Keywords: paraplegia; tetraplegia; atherosclerosis; carbohydrate metabolism; high-density lipoprotein; body composition

\section{Introduction}

Immobilization and paralysis from spinal cord injury (SCI) result in loss of muscle and a relative gain in adiposity. SCI predisposes the individual to medical complications such as lipid abnormalities, carbohydrate intolerance and an atherogenic pattern for coronary heart disease (CHD). One possible etiology for these secondary medical conditions is that they are the result of inactivity in conjunction with adverse body composition changes, which are progressive with advancing age.

A population of veterans with SCI has recently been studied to determine the conventional risk factors for CHD

Correspondence: Dr WA Bauman, Center of Excellence for the Medical Consequences of Spinal Cord Injury, Veterans Affairs Medical Center, 130 West Kingsbridge Road, Room 1E-02, Bronx, NY 10468, USA.

E-mail: william.bauman@va.gov

Received 16 May 2007; revised 26 November 2007; accepted 28 November 2007; published online 8 January 2008 as defined by the Third Report of the National Cholesterol Education Program (NCEP) Expert Panel on Detection, Evaluation, and Treatment of High Blood Cholesterol in Adults (Adult Treatment Panel III). ${ }^{1,2}$ The risk for CHD was determined to be able to set target values for low-density lipoprotein (LDL) cholesterol. Recognizing the potential presence of these metabolic abnormalities and cardiovascular risk in persons with SCI is required for early diagnosis and an improved approach to clinical care. Appropriate interventions are discussed that reduce cardiovascular risk and hold promise to improve longevity and quality of life in persons with SCI.

Soft tissue body composition changes

Longitudinal studies of body composition after acute SCI are limited, but have shown a brisk, marked loss of lean tissue mass. ${ }^{3,4}$ Comparing matched reference populations using 
cross-sectional designs in individuals with chronic SCI, investigators have demonstrated lean tissue loss and/or fat tissue gain. ${ }^{5-7}$ Rasmann Nuhlicek et al. ${ }^{5}$ studied subjects with SCI classified into four levels of lesion subgroups and controls; they found reductions in total body water, intracellular water and lean body tissue and increases in fat mass correlating with the level of neurological deficit. In a cross-sectional study, Spungen et al. ${ }^{6}$ reported significant decreases in percent of regional and total body lean tissue in 132 male subjects equally divided with tetraplegia or paraplegia compared with matched controls. These differences in lean tissue were most pronounced between SCI and control groups in the arms and legs, and less so in the trunk. The subjects with SCI demonstrated a significantly greater reduction of arm percent lean tissue with advancing age than controls (Figure 1a). No difference in the rate of loss was observed between subjects with high or low cord lesions (Figures 1a-d). Compared to able-bodied males who lost about $1 \%$ per decade of total body lean tissue, subjects with SCI lost about $3.2 \%$ per decade. ${ }^{6}$
Due to the individual variability, the ability to determine the precise amount of lean tissue loss and relative or absolute fat tissue gain attributable to paralysis rather than genetics and/or environmental factors is problematic. Longitudinal studies in those with SCI are difficult to perform-that is, capturing body composition immediately after SCI and then sequentially for decades thereafter. A solution to determining changes in body composition, independent of genetic variability and aging, and somewhat controlling for environment, is the use of a cross-sectional monozygotic twin model. In an identical twin study, with one co-twin in each pair having SCI, Spungen et al. ${ }^{7}$ reported a loss of total body and extremity muscle mass that was continuous and directly related to the duration of injury. On average, about $4 \mathrm{~kg}$ of total body lean tissue was lost with each 5-year period of paralysis. ${ }^{7}$

The losses in lean body tissue, a high-energy body compartment, are directly reflected in the metabolic rate. In 13 subjects with SCI, as well as in the non-SCI twins, a strong relationship was shown between metabolic rate and
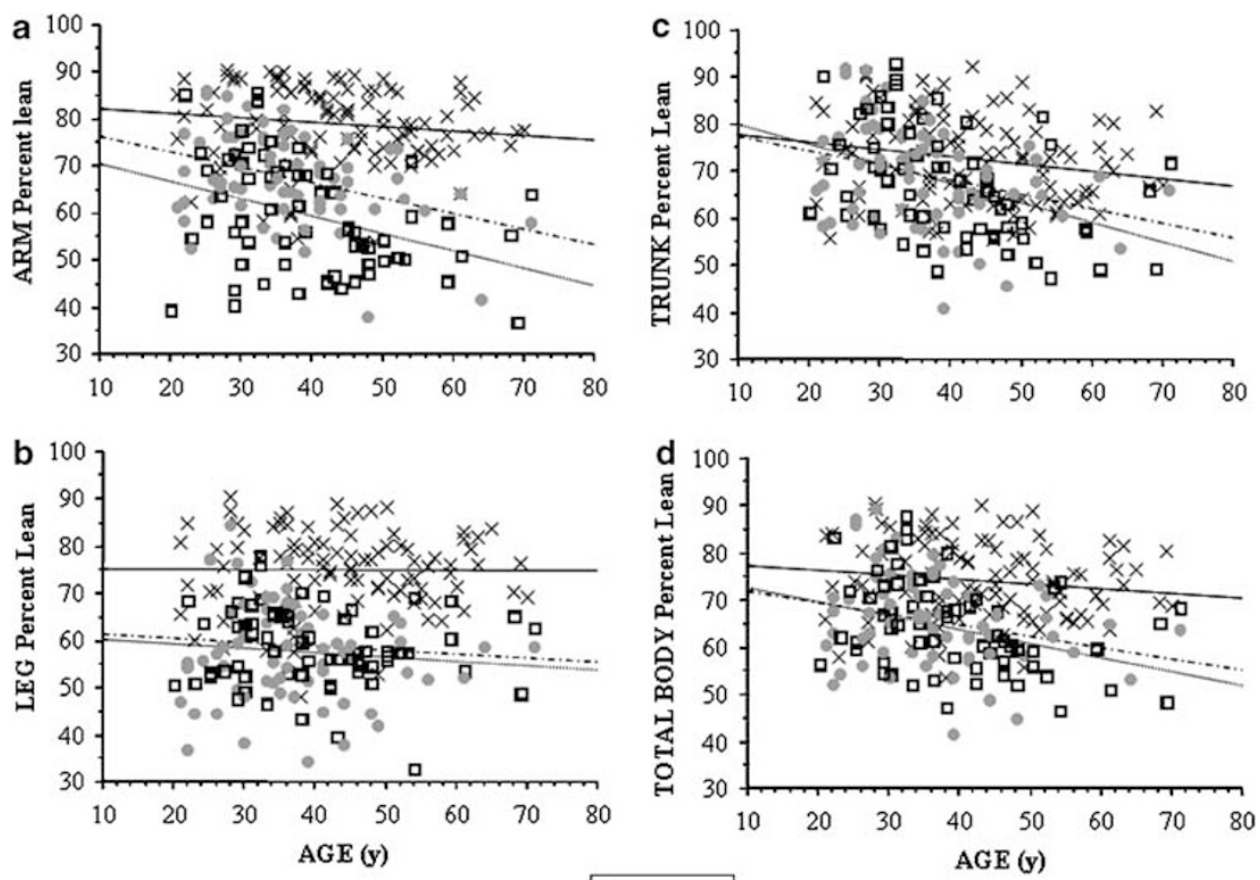

$$
\begin{aligned}
& -x-\text { Cont } \\
& -\bullet-. \text { Para } \\
& -\square-\text { Tetra }
\end{aligned}
$$

Figure 1 Regional and total body lean tissue percent comparisons among controls and persons with tetraplegia (Tetra) and paraplegia (Para). Data represent cross-sectional differences for age among the groups. Slopes $R$ - and $P$-values for each as follows: (a) Arm: Cont, control (slope $=-0.09 ; 95 \% \mathrm{Cl},-0.229,0.049 ; R=0.13 ; P=0.01$ ); Para, paraplegia (slope $=-0.327 ; 95 \% \mathrm{Cl},-0.534,-0.120 ; R=0.37 ; P<0.005$ ); and Tetra, tetraplegia (slope $=-0.373 ; 95 \% \mathrm{Cl},-0.619,-0.127 ; R=0.36 ; P<0.005)$. (b) Leg: Cont (slope $=-0.005 ; 95 \% \mathrm{Cl},-0.146,0.136$; $R=0.01 ; P=N S) ;$ Para (slope $=-0.093 ; 95 \% \mathrm{Cl},-0.337,0.151 ; R=0.09 ; P=\mathrm{NS}) ;$ Tetra (slope $=-0.084 ; 95 \% \mathrm{Cl},-0.265,0.101 ; R=0.12 ;$ $P=$ NS). (c) Trunk: Cont (slope $=-0.158 ; 95 \% \mathrm{Cl}, 0.008,0.333 ; R=0.20 ; P<0.05$ ); Para (slope $=-0.307 ; 95 \% \mathrm{Cl}, 9.073,0.549 ; R=0.31$; $P<0.01$ ); Tetra (slope $=-0.415 ; 95 \% \mathrm{Cl}, 0.189,0.631 ; R=0.42 ; P<0.001)$. (d) Total body: Cont (slope $=-0.102 ; 95 \% \mathrm{Cl},-0.241,0.038 ;$ $R=0.14 ; P=\mathrm{NS}$ ); Para (slope $=0.238 ; 95 \% \mathrm{Cl},-0.456,-0.019 ; R=0.26 ; P<0.005$ ); Tetra (slope $=-0.296 ; 95 \% \mathrm{Cl},-0.492,-0.100$; $R=0.36 ; P<0.005$ ). There was no overlap in $\mathrm{Cls}$ in the panels between the control and the groups with spinal cord injury ( $\mathrm{SCl}$; Para and Tetra). A significant difference in the slope of the lines for (a) was noted between the control and the $\mathrm{SCl}$ groups, but not for the other panels. (reproduced with permission from Spungen, et al. Factors influencing body composition in persons with spinal cord injury: a cross-sectional study. J Appl Physiol 2003; 95: 2398-407). 

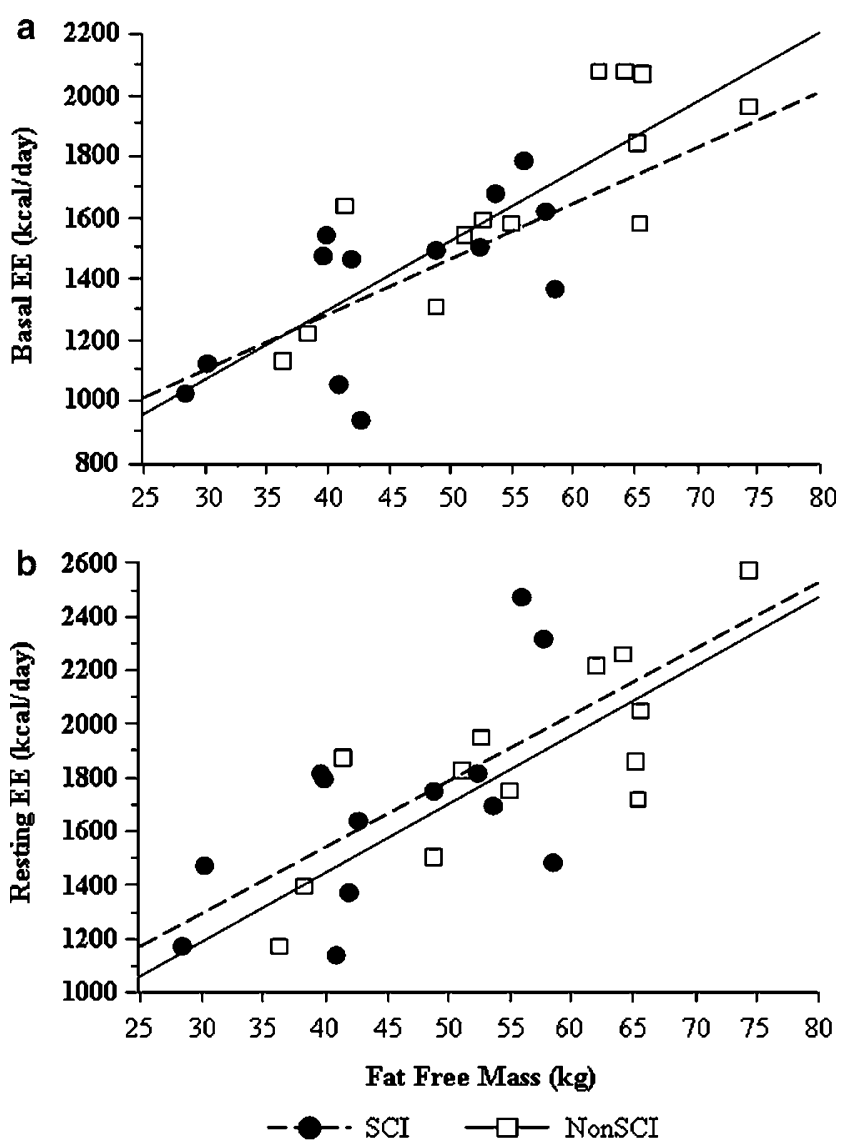

Figure 2 Relationship between energy expenditure and fat-free mass in monozygotic twins discordant for spinal cord injury ( $\mathrm{SCl})$. Linear regression analyses between fat-free mass and energy expenditure. (a) Basal energy expenditure (EE) ( $\mathrm{SCl}$ : slope $=17.98$; $95 \% \mathrm{Cl}, 4.66,31.304 ; R=0.63 ; P<0.05$; non-SCl: slope $=22.517$; $95 \% \mathrm{Cl}, 12.295,32.740 ; R=0.80 ; P<0.001)$ and $(b)$ resting $\mathrm{EE}(\mathrm{SCl}:$ slope $=24.242 ; 95 \% \mathrm{Cl}, 3.967,44.517 ; R=0.67 ; P<0.05 ;$ non-SCl: slope $=25.484 ; 95 \% \mathrm{Cl}, 13.002,37.965 ; R=0.82 ; P<0.0005$ reproduced with permission from Bauman et al. Relationship between $\mathrm{EE}$ and fat-free mass in monozygotic twins discordant for spinal cord injury. J Rehabil Research Dev 2004; 4:1-8).

fat-free mass: the greater reductions in lean body tissue the greater the decreases in resting metabolic rate (Figures $2 \mathrm{a}$ and b). ${ }^{8}$ This supported earlier work by Mollinger et al. ${ }^{9}$ who described a 12-29\% reduction from predicted values for basal energy by the Harris-Benedick equation for energy expenditure in subjects with SCI: the higher the level of injury (and presumably less lean tissue mass) the greater the reduction in basal energy expenditure.

In persons with SCI, the usual clinical measures of total body fat (for example, weight or body mass index (BMI)) underestimate the degree of adiposity. ${ }^{6,10}$ Body fat topography in able-bodied individuals is clearly an important factor associated with metabolic disorders, and it probably is as well in persons with SCI. ${ }^{11,12}$ Related to these adverse body compositional changes and reduced levels of activity, individuals with SCI have a pattern of metabolic alteration that would be considered to be atherogenic. ${ }^{1,2,12}$

\section{Carbohydrate metabolism in SCI}

Impaired glucose tolerance (IGT) and diabetes mellitus (DM) occur more frequently in persons with SCI than in the ablebodied population. ${ }^{13-16}$ Peripheral resistance of insulin to mediate glucose uptake may be demonstrated in most individuals with SCI who have a disorder in glucose tolerance. Mild deteriorations in oral glucose tolerance are associated with insulin resistance and hyperinsulinemia, and this metabolic milieu is recognized as atherogenic. ${ }^{17}$ Worsening of carbohydrate tolerance will ensue if the pancreas' compensatory response is insufficient, as may be expected to occur with advancing age.

Bauman et al. ${ }^{13}$ performed a standard oral glucose tolerance test in 100 subjects with all levels of SCI and in 50 able-bodied controls. ${ }^{13}$ In subjects with SCI, $22 \%$ were diabetic by criteria established by the World Health Organization, whereas only $6 \%$ of the control group were diabetic. ${ }^{13,18}$ A total of $82 \%$ of the controls had normal oral glucose tolerance, compared with $38 \%$ of those with quadriplegia and 50\% of those with paraplegia. Subjects with SCI had significantly higher mean plasma glucose and insulin values at the later time points during the oral glucose tolerance test when compared with controls. The group with SCI had significantly higher sum plasma glucose values at younger ages after an oral glucose load. Values for insulin sensitivity were significantly related to level of fitness, and directly correlated with lean body mass and indirectly correlated with adiposity, although failing to reach significance for the body composition changes. ${ }^{13}$ Tharion et al. ${ }^{16}$ performed oral glucose tolerance testing in persons with SCI as part of their annual medical care in South India. Fasting hyperglycemia was present in 19 and 23\% had elevated values at $2 \mathrm{~h}$ after a glucose load. ${ }^{16}$

The relationship between oral carbohydrate tolerance and several variables, including level and completeness of lesion, gender, ethnicity, age, duration of injury and calculated percent body fat, was studied. ${ }^{14}$ Subjects with complete tetraplegia had significantly worse carbohydrate tolerance with greater peak and sum plasma insulin concentrations and were more frequently classified with a disorder in carbohydrate tolerance than the other neurological deficit subgroups (Figure 3). The glucose curves were not significantly different between men and women, but the plasma insulin levels at the intermediate time points were significantly higher for men than women, suggesting a state of relative insulin resistance in men. Stepwise regression analyses demonstrated that peak serum glucose was significantly associated with increased total body percent fat, complete tetraplegia, older age and male gender; the peak plasma insulin was associated with increased total body percent fat and male gender. In this study, glucose tolerance appeared to be independent of the effects of ethnicity, and glucose abnormalities generally increased with advancing age. ${ }^{14}$

Studies in able-bodied individuals have established associations between hypertension, hyperinsulinemia, obesity and disorders of glucose tolerance, and these associations are being reported in persons with SCI. ${ }^{12,14,19-22}$ The fasting plasma glucose has been shown to highly correlate with 

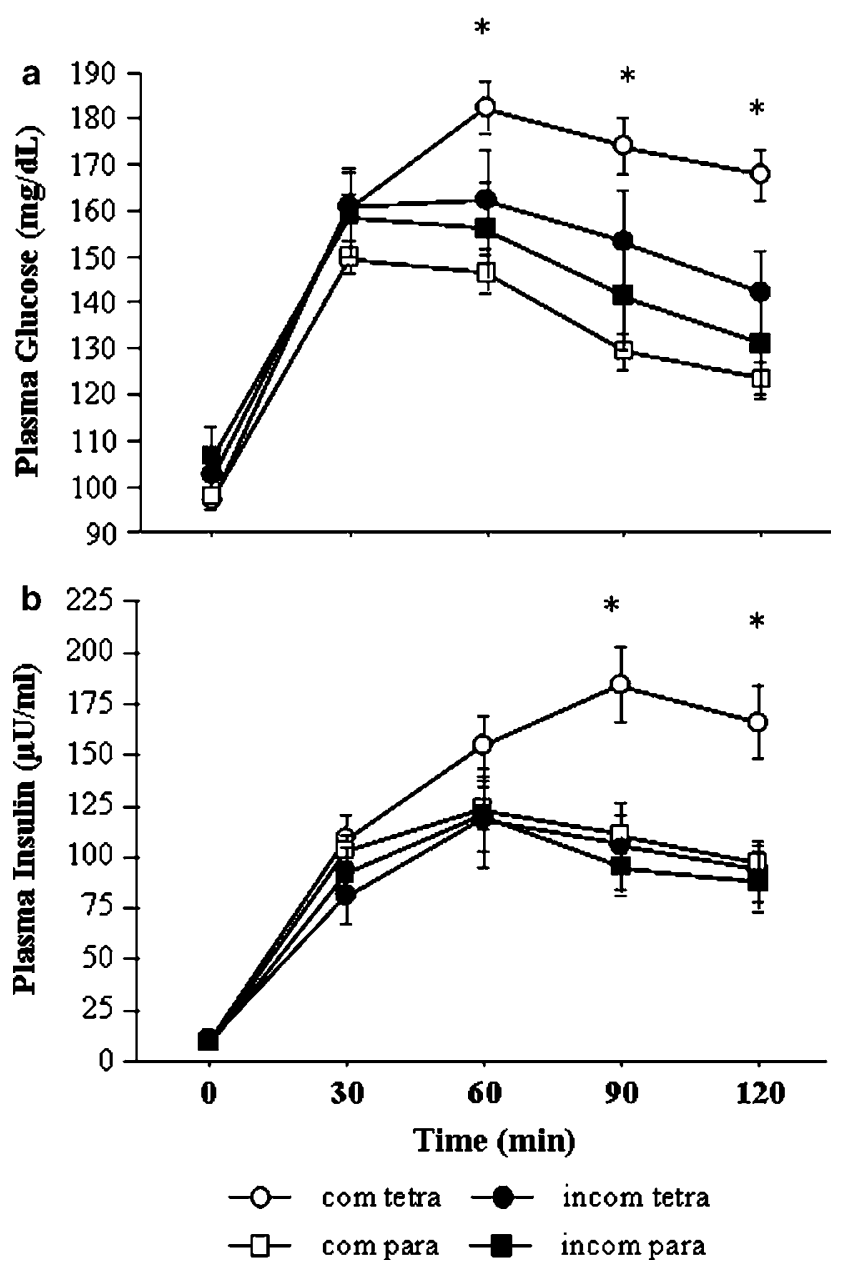

Figure 3 Comparison of oral glucose tolerance by neurological deficit. Shown is the serum glucose concentration vs time after a $2 \mathrm{~h}$ oral glucose tolerance test (a) and the plasma insulin levels vs time after a $2 \mathrm{~h}$ oral glucose tolerance test (b). An asterisk (*) above the time point represents significant differences $(P<0.05)$ between the motor complete tetraplegia group and the three other neurological deficit groups, performed by ANOVA applying a Scheffe's post hoc $\mathrm{F}$ ratio (incomplete tetraplegia, complete paraplegia, incomplete paraplegia reproduced with permission from Bauman WA, Adkins $\mathrm{RH}$, Spungen AM, et al. The effect of residual neurological deficit on oral glucose tolerance in persons with chronic spinal cord injury. Spinal Cord 1999; 37: 765-771).

basal rates of hepatic glucose output. ${ }^{22}$ Because the average fasting plasma glucose is generally within the normal range or only mildly elevated in subjects with SCI, peripheral insulin resistance is the major factor responsible for glucose intolerance. Possibly reflecting a state of insulin resistance, an increased prevalence of hypertension has been reported in persons with chronic paraplegia. ${ }^{23}$ Insulin resistance is also prominent in those with chronic tetraplegia, but because of overriding vasomotor factors that lower blood pressure (for example, attenuated sympathetic nervous system regulation), chronic hypertension is infrequently observed. In a subset of subjects with SCI, hyperuricemia has been reported, another finding related to hyperinsulinemia. ${ }^{24}$

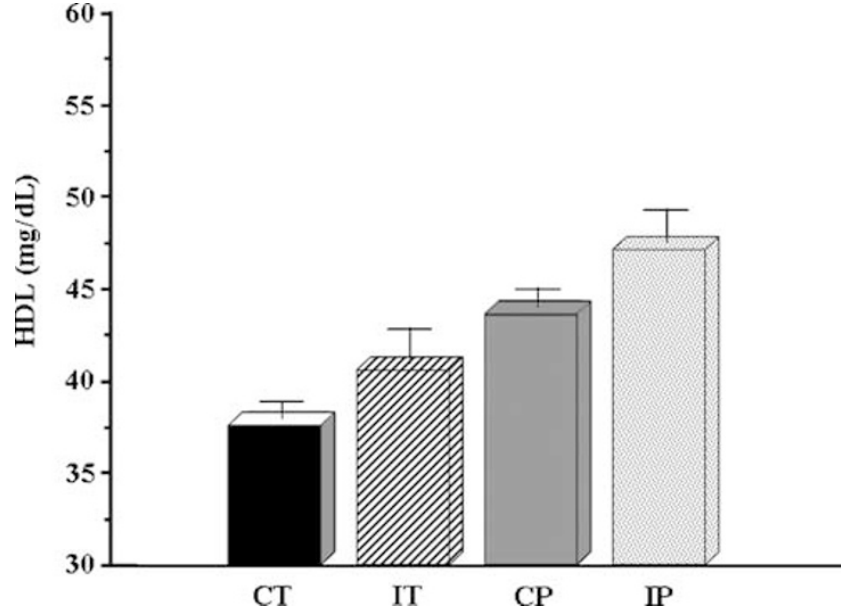

Figure 4 Serum high-density lipoprotein (HDL) cholesterol levels by neurological deficit. Tetra, tetraplegia; Para, paraplegia. Values are expressed in mean \pm s.e.m. (reproduced with permission from Bauman et al. The effect of residual neurological deficit on serum lipoproteins in individuals with chronic spinal cord injury. Spinal Cord 1998; 36: 13-17).

Lipid metabolism and cardiovascular disease

Elevation in LDL cholesterol and depression of high-density lipoprotein (HDL) cholesterol are two important risk factors for $\mathrm{CHD}^{25,26}$ Individuals with SCI are believed to have premature CHD. Approximately 10\% of the US population has HDL cholesterol values $<35 \mathrm{mg}$ per $100 \mathrm{ml}$, whereas about $24-40 \%$ of those with chronic SCI have levels below this value for HDL cholesterol. ${ }^{22,26-29}$ Although the mechanism by which low levels of HDL cholesterol predispose to $\mathrm{CHD}$ is uncertain, it has been postulated that HDL cholesterol is vital for reverse cholesterol transport, which mobilizes cholesterol from the arterial wall, as well as antioxidant, antiinflammatory, antiplatelet and anticoagulant effects. ${ }^{30}$ In subjects with chronic SCI and in controls, an inverse correlation has been demonstrated between serum triglycerides (TGs) and HDL cholesterol, a relationship that may reflect the effects of elevated plasma insulin. ${ }^{22,31-33}$ Maki et al. ${ }^{12}$ found a significant indirect correlation between abdominal circumference and serum HDL cholesterol and a direct correlation with serum TG values, as well as for the ratio of total to HDL cholesterol. Indeed, in persons with SCI, a significant relationship was shown between serum HDL cholesterol and insulin sensitivity, as determined by the minimal-model method. ${ }^{13}$ Subjects with chronic tetraplegia had lower levels of serum HDL cholesterol than those with paraplegia $(38 \pm 0.7$ vs $45 \pm 0.8 \mathrm{mg}$ per $100 \mathrm{ml}, P<0.1) .{ }^{20}$ Subjects with motor complete injury tend to have lower values of serum HDL cholesterol than those with motor incomplete within the subgroups of tetraplegia and paraplegia (Figure 4); a significant, albeit weak, inverse relationship was found for degree of neurological deficit and serum HDL level $(R=0.19, P<0.0001)$; however, no significant difference was noted between complete and incomplete lesions for those with paraplegia or tetraplegia. ${ }^{20}$ Men with SCI had lower HDL cholesterol than control men, but there 


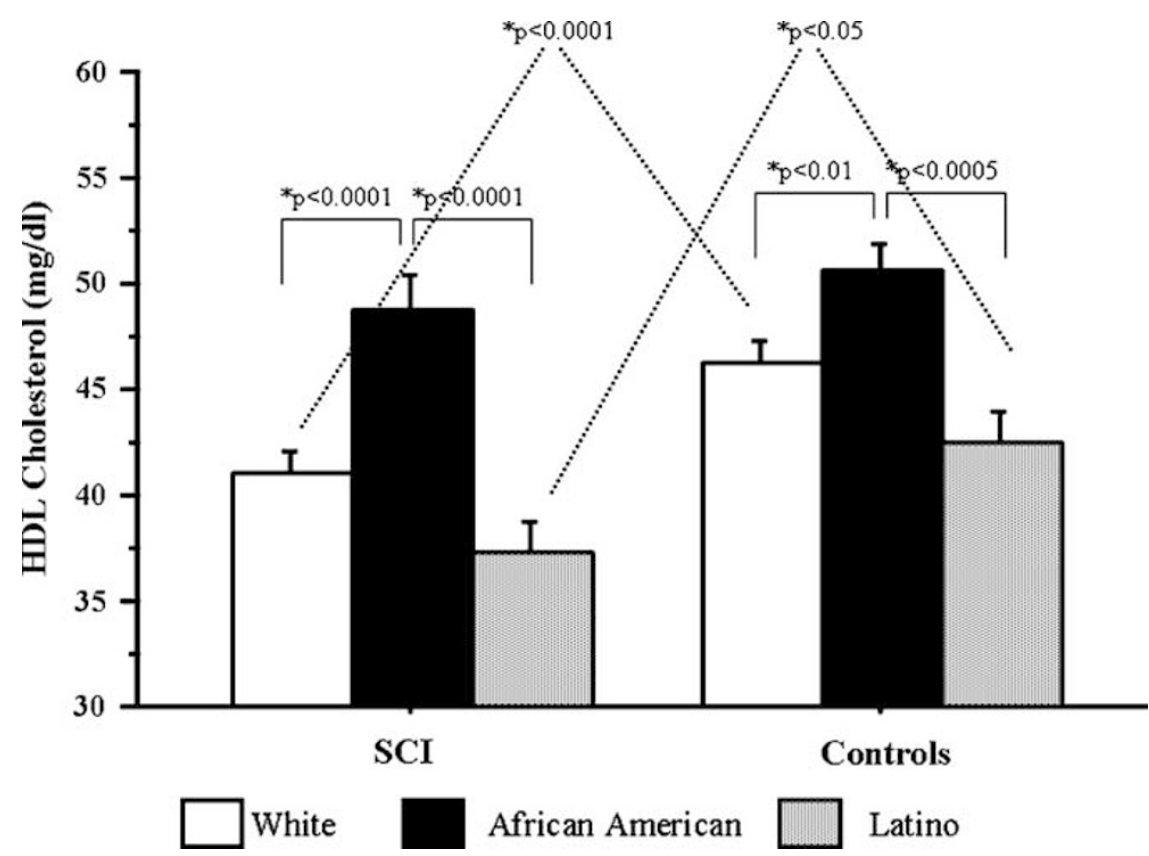

Figure 5 Comparison of serum high-density lipoprotein (HDL) cholesterol among ethnic subgroups. The bar graphs display mean \pm s.e.m. serum HDL cholesterol levels in the groups with spinal cord injury $(\mathrm{SCl})$ and controls stratified by ethnicity. Within (solid lines) and between (dashed lines) group differences are shown (reproduced with permission from Bauman, et al. Carbohydrate and lipid metabolism in chronic spinal cord injury. J Spinal Cord Med 2001; 24:266-277).

was no significant difference found for predominantly premenopausal females with or without SCI. ${ }^{29}$ Caucasians and Latinos with SCI had lower serum HDL cholesterol levels than the ethnic-matched able-bodied group (Figure 5). ${ }^{34}$ African Americans with SCI had significantly higher serum HDL cholesterol values and a lower ratio of serum total to HDL cholesterol than Caucasians or Latinos with SCI, as well as lower serum TGs (Figure 5); of note, and without a known explanation, African Americans with SCI had serum HDL cholesterol values that were not significantly different from African Americans without injury. ${ }^{34}$

At the present time, there are several strategies for raising serum HDL cholesterol. Increasing level of activity, smoking cessation and pharmacological treatment all have been shown to be effective. In persons with or without SCI, increased cardiopulmonary fitness has been demonstrated to raise the serum HDL cholesterol level. ${ }^{22,28,29,35-37}$ In a prior report by our group, persons with paraplegia had significantly higher serum HDL cholesterol values for relatively small increases in maximum oxygen uptake determined by arm ergometry stress testing. ${ }^{13}$ Hooker et al. ${ }^{28}$ demonstrated that moderate-intensity wheelchair ergometry for $20 \mathrm{~min}$, three times per week for 8 weeks, significantly increased HDL cholesterol from $39 \pm 11$ to $47 \pm 8 \mathrm{mg}$ per $100 \mathrm{ml}$, and decreased the ratio of total to HDL cholesterol from $5.0 \pm 0.9$ to $4.0 \pm 0.5$. Circuit resistance training in five men with complete SCI was found to improve peak oxygen consumption by $30 \%$ with an associated $9.8 \%$ increase in HDL cholesterol $(41 \pm 5$ to $45 \pm 12 \mathrm{mg}$ per $100 \mathrm{ml}$ ) and a reduction in the ratio of total to HDL cholesterol of about 1 unit $(5 \pm 1$ to $4 \pm 1) .{ }^{37}$ In the general population, an increase of 1 unit in the ratio of serum total to HDL cholesterol has been found to be associated with a mean increase of $53 \%$ in risk of a coronary event. ${ }^{38}$ Thus, a modest upper exercise regimen that improves cardiovascular fitness may be expected to increase serum HDL cholesterol and reduce CHD risk, although the latter has not been specifically studied in persons with SCI. Inactivity, independent of lipid values or other risk factors for $\mathrm{CHD}$, may be an independent risk factor for CHD. ${ }^{39}$ Persons with SCI should be strongly encouraged to reach and maintain the highest level of daily activity, compatible with their neurological levels of injury.

A Model System Collaborative Study showed that Niaspan $2 \mathrm{~g}$ per day in persons with SCI raised serum HDL cholesterol from $32 \pm 3$ to $40 \pm 7 \mathrm{mg}$ per $100 \mathrm{ml}$, an average increase of $25 \%$, associated with a reduction in serum LDL cholesterol and a significant improvement in TC to HDL ratio from 5.4 to 4.2 (MS Nash, personal communication). In addition to immobilization, high calorie or fat diets may increase plasma TGs and depress serum HDL cholesterol. ${ }^{40}$ In a crosssectional study of outpatients with SCI, persons with shorter duration of injury tended to have higher saturated fat intakes and higher serum TG values than those with longer duration of injury. ${ }^{41}$ Mild-to-moderate alcohol consumption has been reported to increase serum HDL cholesterol levels. ${ }^{42}$ Cigarette smoking has also been shown to be associated with insulin resistance and lower serum HDL cholesterol levels. ${ }^{43}$ In the general population, cigarette smoking has been shown to reduce HDL cholesterol by about $7 \mathrm{mg}$ per $100 \mathrm{ml} .{ }^{44}$ A similar reduction in serum HDL cholesterol may be expected in those with SCI, although it has not been reported. Serum HDL cholesterol levels have been reported 
to increase between 11 and $15 \%$ after smoking cessation. ${ }^{45}$ Current cigarette smoking is an independent risk factor for $\mathrm{CHD}$ and, when reduced or eliminated decreases the risk for CHD. ${ }^{1,2}$

\section{CHD in persons with SCI}

In the able-bodied population, symptoms of $\mathrm{CHD}$ are commonly precipitated by activity, often strenuous. It should be appreciated that the risk of a cardiac event is related to the severity of $\mathrm{CHD}$, not symptoms of $\mathrm{CHD} .{ }^{46}$ The ability of a person with SCI, especially those with higher, more complete lesions, to engage in significant physical activity is often difficult, and, if at all possible, limited. In addition, if an individual with SCI has an ischemic cardiac event, because of nervous interruption of sensory pathways, it may pass unnoticed. Although peripheral vascular disease would be expected to be present because of multiple metabolic cardiovascular disease risk factors, a cigarette smoking prevalence comparable to the able-bodied population and age, it may be undiagnosed in a nonambulatory, older SCI population. Thus, the identification of CHD risk or other macrovascular disease risk equivalents for CHD may be grossly underestimated in those with SCI, requiring a more aggressive approach to determine the presence of atherosclerotic occlusive vascular disease.

Whiteneck et al. ${ }^{47}$ reported that cardiovascular diseases were the most frequent cause of death among persons with SCI more than 30 years after injury ( $46 \%$ of all deaths) and among those more than 60 years of age (35\% of all deaths). Using thallium scintillation stress testing, Bauman et al. ${ }^{48,49}$ found that asymptomatic CHD determined by upper body exercise stress testing was present in 13 of 20 subjects with paraplegia (mean age, 52 years) and by dipyridamole infusion in 4 of 6 subjects with tetraplegia (mean age, 47 years). Lee et al. ${ }^{50}$ determined the prevalence of CHD by thallium ${ }^{201}$ myocardial perfusion single photon computed tomography in 47 asymptomatic patients with SCI, segregated into four groups dependent upon the level (tetraplegia vs paraplegia) and completeness of injury (complete vs incomplete); those with complete tetraplegia had the greatest and those with incomplete paraplegia had the least prevalence of heart disease. Budoff et al. ${ }^{51}$ studied coronary artery calcification (CAC) by electron beam computerized tomography in a group of 91 subjects with SCI who were matched 3:1 with non-SCI controls for age, gender, ethnicity and individual risk factors. In the group with SCI, the investigators found that the mean coronary artery calcium score was significantly greater $(75 \pm 218$ vs $28 \pm 104)$, the prevalence of any CAC was higher (51 vs 39\%), and those with high scores $(>100)$ was greater $(16 \%$ vs $7 \%)$; these findings were not explained by the clustering of traditional risk factors; persons with tetraplegia had a greater prevalence of severe CAC scores than did persons with paraplegia (6.8 vs $2.1 \% ; P<0.05) .{ }^{51}$ Because these studies were of a relatively small sample size, a larger cohort is needed to more accurately determine the prevalence of CHD in the population of persons with SCI. ${ }^{48-51}$

\section{Assessment of risk for CHD}

In the general population, about $25 \%$ of individuals have an elevation of the serum LDL cholesterol level ( $>130 \mathrm{mg}$ per $100 \mathrm{ml}$ ). The level of serum LDL cholesterol in individuals with SCI has been reported to be similar to that of ablebodied persons. The recommendations of the NCEP for therapy are based upon the level of serum LDL cholesterol in association with the presence or absence of CHD or risk factors for CHD. ${ }^{1,2}$ A population of 222 male veterans with SCI (Table 1) was studied to determine the conventional risk factors for CHD as defined by the ATP III guidelines, to calculate the risk for $\mathrm{CHD}$, and to determine the target LDL cholesterol levels for treatment. ${ }^{1,2,52}$ The values for serum total cholesterol, LDL cholesterol and TGs are similar to those in the general population. Of note, the values for HDL cholesterol in those with SCI was shifted to the left (Figure 6d), with mean value of $38 \pm 12 \mathrm{mg}$ per $100 \mathrm{ml}$ in the group with SCI compared with $51 \pm 13 \mathrm{mg}$ per $100 \mathrm{ml}$ in the group of able-bodied controls. The serum TG values for subjects with tetraplegia were significantly lower than those for controls ( $116 \pm 76 \mathrm{vs} 148 \pm 86 \mathrm{mg}$ per $100 \mathrm{ml} ; P<0.0001$ ), whereas no significant difference was found between those with paraplegia and controls; a possible, but unproven, explanation for the depressed TGs in persons with higher cord lesions may be that they were in negative calorie balance, having lost the ability to feed themselves. An inverse relationship was present between BMI and serum HDL cholesterol values (Figure 7a). A direct relationship was noted between BMI and serum TGs (Figure 7b). An inverse relationship was found between serum HDL cholesterol and plasma TGs (Figure 7c). DM was diagnosed on the fasting serum glucose in 5\% of patients, whereas DM was diagnosed in $17 \%$ of subjects on the $2 \mathrm{~h}$ serum glucose value. Hyperinsulinemia was present in $34 \%$ of patients (31\% with tetraplegia vs $18 \%$ with paraplegia). Significant linear relationships were evident for BMI vs fasting or $2 \mathrm{~h}$ plasma insulin levels for those with SCI, with higher BMI values correlating with higher plasma insulin concentrations. ${ }^{52}$

Hypertension was present in $23 \%$ of the entire veteran group; in the subgroups by level of lesion, hypertension was more frequent in those with paraplegia than tetraplegia (32 vs $10 \%$; Table 2). ${ }^{52}$ A total of $34 \%$ of the patients were current cigarette smokers. A positive family history for CHD was noted in $33 \%$ of the patients (Table 2). ${ }^{52} \mathrm{CHD}$ was reported to be present in only $8 \%$ of patients (Table 3 ). Two or more CHD-risk factors were present in the majority of patients (Table 3). By the Framingham scoring system to

Table 1 Characteristics of the study groups

\begin{tabular}{lccc} 
& \multicolumn{1}{c}{ Tetra $(\mathrm{n}=103)$} & Para $(\mathrm{n}=119)$ & \\
\cline { 2 - 4 } & $\mathrm{n}(\%)$ & $\mathrm{n}(\%)$ & P-value \\
\hline Age (year) & $46 \pm 14$ & $52 \pm 14$ & 0.0027 \\
DOI (year) & $16 \pm 12$ & $19 \pm 13$ & 0.0687 \\
BMI (kg m & & \\
& $24.3 \pm 5.2$ & $25.5 \pm 4.4$ & 0.076 \\
\hline
\end{tabular}

Abbreviations: BMI, body mass index; DOI, duration of injury; Tetra, tetraplegia; para, paraplegia. 

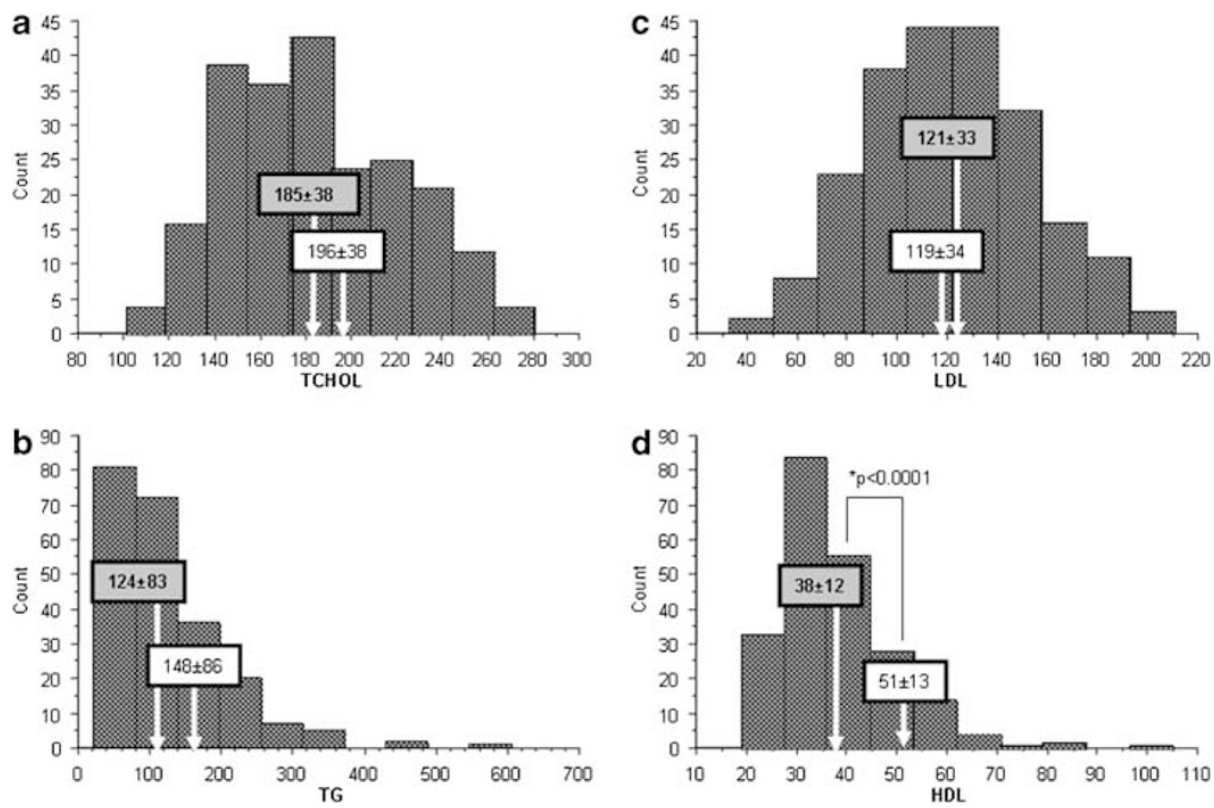

Figure 6 Histogram distribution of serum lipid fractions: Count or number of subjects is represented on the $y$ axis for values of total cholesterol (a), triglycerides (TGs) (b), LDL, low-density lipoprotein cholesterol (c) and HDL, high-density lipoprotein cholesterol (d). The shaded boxes present the mean \pm s.d. for the spinal cord injury $(\mathrm{SCl})$ veteran population; the unshaded boxes present the mean \pm s.d. for the able-bodied veteran population. Note the leftward shift of $\mathrm{HDL}$ cholesterol in the veterans with $\mathrm{SCl}$ (d) (reproduced with permission from Bauman, et al. Risk assessment for coronary heart disease in a veteran population with spinal cord injury. Top Spinal Cord Inj Rehab 2007; 12: 35-53).

determine short-term risk, $54 \%$ of patients with SCI had 10 -year risk of between 10 and $20 \%$, with only 8 of these patients (4\%) having a 10 -year risk of $>20 \%$ (Table 3 ). The increased risk of CHD by NCEP criteria in those with paraplegia was due almost exclusively to the increased prevalence of hypertension in this group compared with those with tetraplegia. It should be appreciated that the NCEP classification does not take into account the greater depression in level of HDL cholesterol in persons with values $<40 \mathrm{mg}$ per $100 \mathrm{ml}$ in those with tetraplegia compared to those with paraplegia; a greater percent of individuals with tetraplegia than those with paraplegia had HDL cholesterol values $<35 \mathrm{mg}$ per $100 \mathrm{ml}$ (51 vs $38 \% ; P=0.05$ ), and for values $<30 \mathrm{mg}$ per $100 \mathrm{ml}$ (25 vs $14 \% ; P=0.05$ ).

\section{Considerations for treatment of LDL cholesterol}

The major CHD risk factors and the stratification of CHD risk with target values for LDL cholesterol have been described for a group of veterans with SCI (Tables 2 and 3). ${ }^{52}$ Twentynine percent of the total group is at high risk of CHD (for example, 35 subjects with CHD or risk equivalents plus an additional three subjects with a 10 -year risk $>20 \%$ ), with $22 \%(28 / 129)$ requiring intervention to lower LDL cholesterol to $<100 \mathrm{mg}$ per $100 \mathrm{ml} ; 45 \%$ (58 subjects) of the total group is at moderate risk of CHD (those with two or more risk factors, a 10 -year risk $\geqslant 10 \%$, and without CHD or risk equivalents for CHD), with 19\% (24 of 129 subjects) requiring intervention to lower $\mathrm{LDL}$ cholesterol to $<130 \mathrm{mg}$ per $100 \mathrm{ml}$ (Table 4 ).

The ATP III treatment recommendations are guidelines to 'inform, not replace' the physician's clinical judgment, which must ultimately determine the appropriate treatment for each individual. Thus, the intensity of risk-reduction therapy should be adjusted to an individual's risk of having an occlusive myocardial event, and special considerations should be operative in different population groups. Men with SCI may have a greater risk because their HDL cholesterol levels are generally lower, with the percentage of those with extremely low serum values being quite remarkable (44\% of the total group having HDL cholesterol values <35 mg per $100 \mathrm{ml}$, and $19 \%$, <30 mg per $100 \mathrm{ml}$ ). Because the magnitude of the HDL cholesterol depression is often more marked in those with SCI than in the general population, the risk of having a coronary event would be expected to rise along a continuum of risk. For each $1 \mathrm{mg}$ per $100 \mathrm{ml}$ decrement in serum HDL cholesterol, the risk of a coronary event increases $2 \%$ in men. ${ }^{53}$ If the serum HDL cholesterol is $\leqslant 30 \mathrm{mg}$ per $100 \mathrm{ml}$, the risk of having a coronary event would be estimated to increase to about $\geqslant 20 \%$, independent of other risk factor assessment. A total of $19 \%$ of the study cohort had serum HDL cholesterol values depressed of this magnitude. ${ }^{52}$ Therefore, a single risk factor may elevate an individual's risk of CHD to a level requiring the practitioner to set a more stringent target criterion for the cut-off value for serum LDL cholesterol than advised in the Framingham scoring system. In contrast to the heightened risk of CHD in men with SCI, premenopausal women with SCI may have a risk of CHD more comparable to that of the general female population because their HDL cholesterol levels were found to be similar. ${ }^{21,29}$

The objective of the treatment of hyperlipidemia is to prevent or reduce the morbidity and mortality associated with CHD. To this end, several treatment programs in the 
Risk factors for coronary artery disease in $\mathrm{SCI}$ WA Bauman and AM Spungen
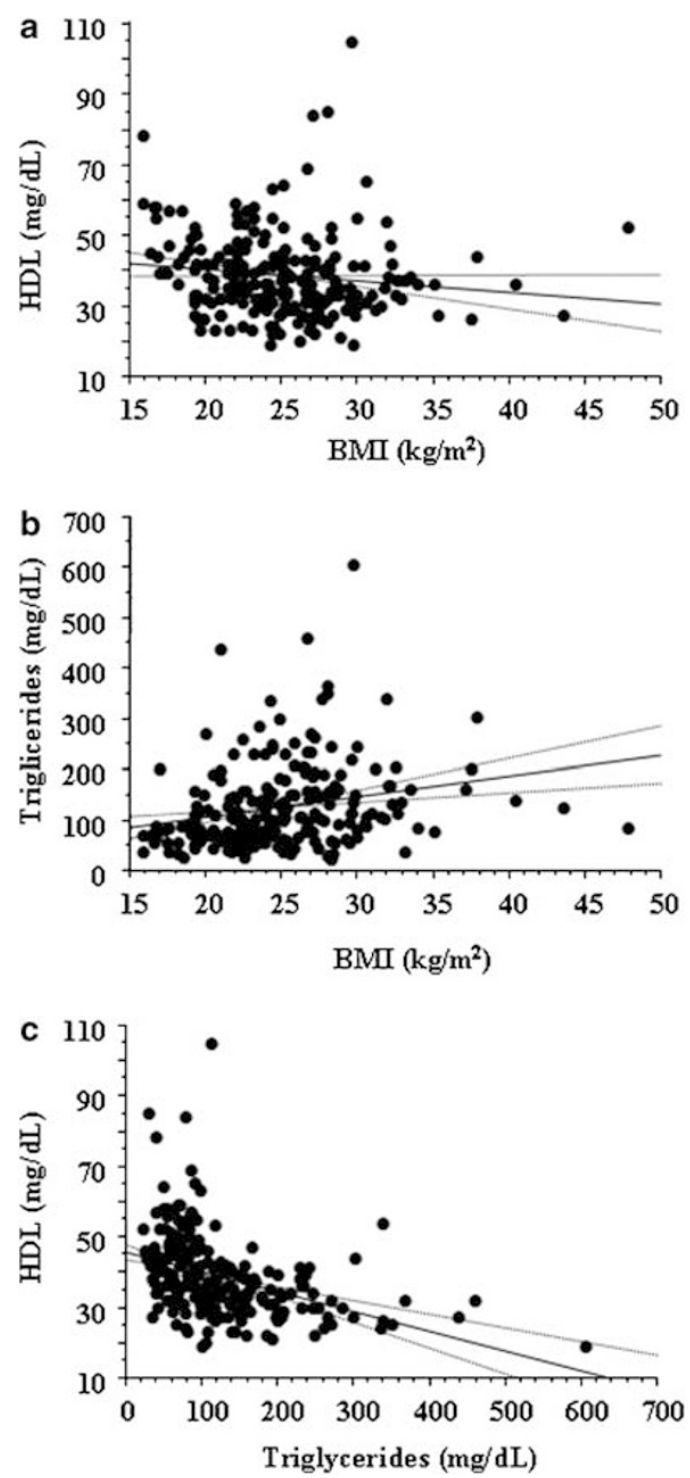

Figure 7 Relationships among high-density lipoprotein (HDL), triglyceride (TG) and body mass index (BMI) in persons with spinal cord injury ( $\mathrm{SCl})$. (a) $\mathrm{HDL}$ cholesterol with $\mathrm{BMI}(R=-0.127$, slope $=-0.315 ; 95 \% \mathrm{Cl},-0.639,0.012 ; P=0.05)$; (b) TG with BMI $(R=0.24$, slope $=4.098 ; 95 \% \mathrm{Cl}, 1.875,6.321 ; P<0.005) ;(\mathrm{c})$ $\mathrm{HDL}$ cholesterol and TG $(R=-0.394$, slope $=-0.056 ; 95 \% \mathrm{Cl}$, $-0.073,-0.039 ; P<0.0001)$. The $\mathrm{Cl}$ has been provided for each line (reproduced with permission from Bauman, et al. Risk assessment for coronary heart disease in a veteran population with spinal cord injury. Top Spinal Cord Inj Rehab 2007; 12: 35-53).

general population have been reported to be successful. Lowfat and -cholesterol diets may be expected to reduce levels of serum LDL cholesterol between 10 and $20 \%$. To maintain a therapeutic benefit, the patient must remain on diet therapy indefinitely. There are two classes of pharmacological agents that are generally used to lower serum LDL cholesterol: hydroxymethylglutaryl-coenzyme A (HMG CoA) reductase inhibitors (statins) and bile acid-binding resins. The bile acid-binding resins may be less desirable in persons with SCI because they have a tendency to cause increased constipation, abdominal flatulence and interfere with the absorption
Table 2 Major risk factors for CHD

\begin{tabular}{lccc}
\hline & \multicolumn{1}{c}{ Tetra $(\mathrm{n}=103)$} & \multicolumn{1}{c}{ Para $(\mathrm{n}=119)$} & \\
\cline { 2 - 3 } Major risk factors & $\mathrm{n}(\%)$ & $\mathrm{n}(\%)$ & P-value \\
\hline Cigarette smoker & $33(31)$ & $41(34)$ & $\mathrm{NS}$ \\
HTN $(\geqslant 140 / 90 \mathrm{~mm} \mathrm{Hg})$ & $10(10)$ & $36(32)$ & 0.0002 \\
Low HDL $(<40 \mathrm{mg} / \mathrm{dl})$ & $67(64)$ & $77(60)$ & $\mathrm{NS}$ \\
Family Hx CHD & $32 / 94(34 \%)$ & $36 / 110(33 \%)$ & $\mathrm{NS}$ \\
Men $\geqslant 45$ year & $54(50)$ & $82(69)$ & 0.005 \\
\hline
\end{tabular}

Abbreviations: Cigarette smoker, current smoker having smoked greater than 100 cigarettes in lifetime; CHD, coronary heart disease; HDL, high-density lipoprotein; HTN, hypertension.

Bauman et al. Top Spinal Cord Inj Rehab 2007; 12: 35-53.

Table 3 Ten-year risk assessment

\begin{tabular}{lccc}
\hline Risk category & Tetra & Para & LDL Goal \\
\hline CHD & $5 / 94(5 \%)$ & $13 / 111(12 \%)$ & $<100$ \\
DM by FPG & $4(4)$ & $7(6)$ & $<100$ \\
DM by OGTT 2h Glu & $18(17)$ & $20(17)$ & $<100$ \\
10-Year Risk $>20 \%$ & $2(2)$ & $6(5)$ & $<100$ \\
2 Risk factors & $64(66)$ & $92(79)^{\star}$ & $<130$ \\
10-Year risk 10-20\% & $42(39)$ & $68(57)^{\star \star}$ & $<130$ \\
0-1 Risk factor & $33(34)$ & $24(21)^{\star}$ & $<160$ \\
10-Year risk $<10 \%$ & $63(59)$ & $45(38)^{\star \star}$ & $<160$ \\
\hline
\end{tabular}

CHD, coronary heart disease; DM, diabetes mellitus; FPG, fasting plasma glucose; OGTT, oral glucose tolerance test.

Bauman et al. Top Spinal Cord Inj Rehab 2007; 12:35-53.

${ }^{*} P<0.05 ;{ }^{* *} P<0.005$.

Table 4 Assessment of risk for coronary heart disease

\begin{tabular}{lcc}
\hline Risk & Subjects $^{\mathrm{a}}(\%)$ & Target value $(\mathrm{mg} / \mathrm{dl})^{\prime}$ \\
\hline CHD or risk equivalents $(n=35)$ & 74 & $<100$ \\
$\geqslant 2$ Risk factors $(\mathrm{n}=61)$ & & \\
$10-$ Year risk $>20 \%$ & 3 & $<100$ \\
$10-$ Year risk $10-20 \%$ & 34 & $<130$ \\
10 -Year risk $<10 \%$ & 5 & $<130$ \\
$0-1$ Risk factor $(n=33)$ & 9 & $<160$
\end{tabular}

Abbreviation: CHD, coronary heart disease.

aPercent of subjects in each group who qualify for intervention based on the ATP III guidelines.

of nutrients and medications, as well as being less potent in their lipid-lowering potential.

Approximately 17-20\% of veterans with SCI were classified as having DM. ${ }^{13,14,52}$ The determinants of insulin resistance are level of cardiovascular fitness, muscle mass and fat mass. ${ }^{54}$ Obesity, physical inactivity and a high-fat diet are recognized risk factors for diabetes, all of which can be modified. DM is a CHD risk equivalent, and, therefore, the target value for LDL cholesterol is $<100 \mathrm{mg}$ per $100 \mathrm{ml}$. In one report, $87 \%$ patients with classifiable DM would have been missed if relying on only the fasting plasma glucose value rather than the 2 -h time point in an oral glucose tolerance test, underscoring the need to perform provocative testing. ${ }^{52}$

Persons with paraplegia have been reported to have an increased prevalence of hypertension. ${ }^{23}$ If one assumes an 
increased frequency of hypertension in the individuals with paraplegia, then an increase in those with pre-hypertensive values is also likely. Indeed, reduced baroreceptor sensitivity has been shown in this population, which is appreciated to be an antecedent condition to the development of hypertension. ${ }^{55}$ In a recent report, there appears to be an increased risk of developing cardiovascular disease, predominantly CHD, in persons with pre-hypertension (blood pressure $120 / 80$ to $139 / 89$ ) compared with those with optimal blood pressure levels. ${ }^{56}$ Compensatory increased activity of the renin-angiotensin system to maintain hemodynamic stability by vasoconstriction and increased cardiac contractility is present in those with higher cord lesions (for example, above thoracic level-6). Elevated levels of angiotensin II may also increase collagen and myocyte growth, oxidative stress, inflammation and coagulability, which may be associated with the development and progression of cardiovascular disease, a consideration not captured by the conventional assignment of risk for CHD.

\section{Potential problems with the criteria for metabolic syndrome in persons with SCI}

The ATP III guidelines specifically identified the metabolic syndrome as a multiplex risk factor of cardiovascular disease and established criteria to better define it. ${ }^{1,2}$ Persons with SCI may not be easily categorized by the ATP III criteria for the metabolic syndrome, or by criteria of other organizations. ${ }^{2,57,58}$ Because the ATP III criteria for the metabolic syndrome are the most commonly used in the United States, this discussion focuses on its definition, although a similar line of reasoning may be applied to the other classifications.

To satisfy the ATP III criteria, three of five risk factor criteria must be present (abdominal obesity by waist circumference, blood pressure and levels of TGs, HDL cholesterol, and fasting glucose). ${ }^{1,2}$ Those with SCI may be relatively obese because of the loss of muscle mass, but this may not be quantifiable by performing a waist circumference measurement. Blood pressure values are generally lower in persons with higher cord lesions than those in the general population. In those with SCI, the fasting serum glucose is usually within the normal range, despite frequently significant insulin resistance and hyperinsulinemia. If an oral glucose tolerance test is performed, the persons with SCI may be classified as having IGT or DM (performing this provocative study is not a criterion for diagnosis of the syndrome by the ATP III guidelines). Despite an inverse relationship demonstrated between TG and HDL cholesterol, patients with SCI often have fasting TG levels $<150 \mathrm{mg}$ per $100 \mathrm{ml}$. Thus, individuals with SCI may not satisfy criteria for the metabolic syndrome, as defined by ATP III, or, for that matter, other classifications.

Finally, in the general population the determination of the presence or absence of the metabolic syndrome does not appear to confer additive risk over and above that of the conventional risk factors for CHD. ${ }^{59}$ Because of the aforementioned considerations, it is crucial to be knowledgeable of the underlying metabolic pathophysiology of those with SCI.

\section{Conclusion}

Adverse changes in body composition and inactivity predispose persons with SCI to metabolic abnormalities that tend to accelerate the development and appearance of CHD. Atrophy of muscle and absolute and/or relative increases in body fat occur shortly after injury, continuing at an increased rate in persons with SCI with advancing age. Insulin resistance and hyperinsulinemia develop with associated disorders in carbohydrate and lipid metabolism. The ability of the pancreas to compensate for these changes may diminish with duration of injury and advancing age.

Conventional risk factors for CHD were identified in a population of veteran outpatients with SCI. After persons with known DM were excluded, approximately $17 \%$ were classified as having DM on oral glucose tolerance testing and $39 \%$ had two or more risk factors for CHD. Compared with the general population, in subjects with SCI serum HDL cholesterol values were shifted to the left with several patients having extremely low levels, highlighting the need that HDL cholesterol be recognized as a risk factor requiring special consideration with regard to therapeutic intervention. Persons with paraplegia may have increased hypertension and pre-hypertension, increasing CHD risk. Individuals with tetraplegia may have relatively low blood pressure values but compensatory elevated levels of angiotensin II to maintain blood pressure during upright posture; elevated levels of angiotensin II are appreciated to have a myriad of deleterious effects on the vasculature. The absence of activity and symptoms of cardiovascular disease in this population may reduce identification of macrovascular disease and may hinder the correct stratification of CHD risk for the cut-off values for serum LDL cholesterol by the ATP III guidelines. From various noninvasive imaging approaches, CHD appears to occur prematurely in those with SCI, and, of interest, may not be as closely related to traditional risk factors as has been demonstrated in the able-bodied population. Because of idiosyncrasies of the population, persons with SCI may not be classified by the established criteria as having the 'metabolic syndrome', despite being inactive and relative obesity with associated metabolic disorders that predispose them to an increased risk of CHD. The conventional risk factors in individuals with SCI should be identified and aggressively treated according to current standards of care.

\section{Acknowledgements}

We wish to acknowledge the Department of Veterans Affairs Rehabilitation Research and Development Service, James J Peters Veterans Affairs Medical Center, United Spinal Association (formally Eastern Paralyzed Veterans Association) and Spinal Cord Research Foundation.

\section{References}

1 Expert Panel on Detection, Evaluation, and Treatment of High Blood Cholesterol in Adults. Executive summary of the Third Report of the National Cholesterol Education Program (NCEP) Expert Panel on Detection, Evaluation, and Treatment of High 
Blood Cholesterol in Adults (Adult Treatment Panel III). JAMA 2001; 285: 2486-2497.

2 National Cholesterol Education Program (NCEP) Expert Panel on Detection, Evaluation, and Treatment of High Blood Cholesterol in Adults (Adult Treatment Panel III). Third Report of the National Cholesterol Education Program (NCEP) Expert Panel on Detection, Evaluation, and Treatment of High Blood Cholesterol in Adults (Adult Treatment Panel III) final report. Circulation 2002; 106: 3143-3421.

3 Wilmet E, Ismail AA, Heilporn A, Welraeds D, Bergmann P. Longitudinal study of bone mineral content and soft tissue composition after spinal cord section. Paraplegia 1996; 33: 674-677.

4 Rossier $\mathrm{AB}$, Favre $\mathrm{H}$, Valloton $\mathrm{MB}$. Body composition and endocrine profile in spinal cord injured patients. In: Lee BY, Ostrander E, George J, Cochran B, Shaw WW (eds). The Spinal Cord Injured Patient, Chapter 13, Comprehensive Management: WB Saunders Co.: Philadelphia, PA, 1991, pp 163-170.

5 Rasmann Nuhlicek DN, Spurr GB, Barboriak JJ, Rooney CB, El Ghatt AZ, Bongard RD. Body composition of patients with spinal cord injury. Euro J Clin Nutr 1988; 42: 765-773.

6 Spungen AM, Adkins RH, Stewart CA, Wang J, Pierson Jr RN, Waters RL et al. Factors influencing body composition in persons with spinal cord injury: a cross-sectional study. J Appl Physiol 2003; 95: 2398-2407.

7 Spungen AM, Wang J, Pierson Jr RN, Bauman WA. Soft tissue body composition differences in monozygotic twins discordant for immobilization. J Applied Physiol 2000; 88: 1310-1315.

8 Spungen AM, Bauman WA, Wang J, Pierson Jr RN. The relationship between total body potassium and resting energy expenditure in individuals with paraplegia. Arch Phys Med Rehabil 1993; 73: 965-968.

9 Mollinger LA, Spurr GB, El Ghatit AZ, Barboriak JJ, Rooney CB, Davidoff DD et al. Daily energy expenditure and basal metabolic rates of patients with spinal cord injury. Arch Phys Med Rehabil 1985; 66: 420-426.

10 Bauman WA, Spungen AM, Zhong YG, Mobbs CV. Plasma leptin is directly related to body adiposity in subjects with spinal cord injury. Horm Metab Res 1997; 28: 732-736.

11 Kissebah AH, Vydelingum N, Murray R, Evans DJ, Hartz AJ, Kalkhoff RK et al. Relation of body fat distribution to metabolic complications of obesity. J Clin Endocrinol Metab 1982; 54: 254-260.

12 Maki KC, Briones ER, Lanbein WE, Inman-Felton A, Nemchausky $\mathrm{B}$, Welch $\mathrm{M}$ et al. Associations between serum lipids and indicators of adiposity in men with spinal cord injury. Paraplegia 1995; 33: 102-109.

13 Bauman WA, Spungen AM. Disorders of carbohydrate and lipid metabolism in veterans with paraplegia or quadriplegia: a model of premature aging. Metabolism 1994; 43: 749-756.

14 Bauman WA, Adkins RH, Spungen AM, Waters RL. The effect of residual neurological deficit on oral glucose tolerance in persons with chronic spinal cord injury. Spinal Cord 1999; 37: 765-771.

15 Duckworth WC, Solomon SS, Jallepalli P, Heckemeyer C, Finnern $\mathrm{J}$, Powers A. Glucose intolerance due to insulin resistance in patients with spinal cord injuries. Diabetes 1980; 29: 906-910.

16 Tharion G, Prasad KR, Gopalan L, Bhattacharji S. Glucose intolerance and dyslipidaemias in persons with paraplegia and tetraplegia in South India. Spinal Cord 1998; 36: 228-230.

17 Haffner SM, Stern MP, Hazuda HP, Mitchell BD, Patterson JK. Cardiovascular risk factors in confirmed prediabetic individuals. Does the clock for coronary heart disease start ticking before the onset of clinical diabetes? JAMA 1990; 263: 2893-2898.

18 WHO Expert Committee on Diabetes Mellitus: second report WHO Tech Rep Ser no. 646, 1980.

19 Modan M, Halkin H, Almog S, Lusky A, Eshkol A, Shefi M et al. Hyperinsulinemia: a link between hypertension, obesity and glucose intolerance. J Clin Invest 1985; 75: 809-817.

20 Bauman WA, Adkins RH, Spungen AM, Kemp BJ, Waters RL. The effect of residual neurological deficit on serum lipoproteins in individuals with chronic spinal cord injury. Spinal Cord 1998; 36: $13-17$.
21 Bauman WA, Spungen AM, Zhong YG, Rothstein JL, Petry C, Gordon SK. Depressed serum high density lipoprotein cholesterol levels in veterans with spinal cord injury. Paraplegia 1992; 30: 697-703.

22 Campbell PJ, Mandarino LJ, Gerich JE. Quantification of the relative impairment in actions of insulin on hepatic glucose production and peripheral glucose uptake in NIDDM. Metabolism 1988; 37: 15-21.

23 Yekutiel M, Brooks ME, Ohry A, Yarom J, Carel R. The prevalence of hypertension, ischemic heart disease and diabetes in traumatic spinal cord injured patients and amputees. Paraplegia 1989; 27: $58-62$.

24 Zhong YG, Levy E, Bauman WA. The relationships among serum uric acid, plasma insulin, and serum lipoproteins in subjects with spinal cord injury. Horm Metab Res 1995; 27: 283-286.

25 Castelli WP, Leaf A. Identification and assessment of cardiac risk-an overview. Cardiol Clin 1985; 3: 171-178.

26 Grundy SM, Goodman MD, Rifkind BM, Cleeman JI. The place of HDL cholesterol management. A perspective from the National Cholesterol Education Program. Arch Intern Med 1989; 149: 505-510.

27 Brenes G, Dearwater S, Shapera R, LaPorte RE, Collins E. High density lipoprotein cholesterol concentrations in physically active and sedentary spinal cord injured patients. Arch Phys Med Rehabil 1986; 67: 445-450.

28 Hooker SP, Wells CL. Effects of low-and moderate-intensity training in spinal cord-injured persons. Med Sci Sports Exerc 1989; 21: 18-22.

29 Bauman WA, Adkins RH, Spungen AM, Herbert R, Schechter C, Smith D et al. Is immobilization associated with an abnormal lipoprotein profile? Observations from a diverse cohort. Spinal Cord 1999; 37: 485-493.

30 Rader DJ. High-density lipoproteins and atherosclerosis. Am J Cardiol 2002; 90 (Suppl): 62i-70i.

31 Johansson J, Walldius G, Carlson LA. Close correlation between high-density lipoprotein and triglycerides in normotriglyceridemia. J Int Med 1992; 232: 43-51.

32 Golay A, Zech L, Shi MZ, Chiou YA, Reaven GM, Chen YD. High density lipoprotein (HDL) metabolism in noninsulin-dependent diabetes mellitus: measurement of HDL turnover using tritiated HDL. J Clin Endocrinol Metab 1987; 65: 512-518.

33 Reaven GM, Greenfield MS. Diabetic hypertriglyceridemia Evidence for three clinical syndromes. Diab 1981; 30 (Suppl 2): 66-75.

34 Bauman WA, Adkins RH, Spungen AM, Maloney P, Gambino R, Waters RL. Ethnicity effect on the serum lipid profile in persons with spinal cord injury. Arch Phys Med 1998; 79: 176-180.

35 LaPorte RE, Brenes G, Dearwater S, Murphy MA, Cauley JA, Dietrick R et al. HDL cholesterol across a spectrum of physical activity from quadriplegia to marathon running (letter). Lancet 1983, 1212-1213.

36 Kraus WE, Houmard JA, Duscha BD, Knetzger KJ, Knetzger KJ, Wharton MB, McCartney JS et al. Effects of the amount and intensity of exercise on plasma lipoproteins. N Engl J Med 2002; 347: 1483-1492.

37 Nash MS, Jacobs PL, Mendex AJ, Goldberg RB. Circuit resistance training improves the atherogenic lipid profiles of persons with chronic paraplegia. J Spinal Cord Med 2001; 24: 2-9.

38 Stampfer MJ, Sacks FM, Salvini S, Willett WC, Hennekens CH. A prospective study of cholesterol, apolipoproteins, and the risk of myocardial infarction. N Eng J Med 1992; 325: 373-381.

39 Bauman A, Owen N. Habitual physical activity and cardiovascular risk factors. Med J Aust 1991; 154: 22-28.

40 Schlierf G, Reinhemer W, Stosberg V. Diurinal patterns of plasma triglycerides and free fatty acids in normal subjects and in patients with endogenous (type IV) hyperlipidemia. Nutr Metabol 1971; 13: 80-91.

41 Moussavi RM, Ribas-Cardus F, Rintala DH, Rodriguez GP. Dietary and serum lipids in individuals with spinal cord injury living in the community. J Rehab Res Dev 2001; 38: 225-233.

42 Hully S, Gordon S. Alcohol and high-density lipoprotein cholesterol. Causal inference from diverse study designs. Circulation 1981; 64 (Supp III): 57-63. 
43 Facchini FS, Hollenbeck CB, Jeppesen J, Chen YD, Reaven GM. Insulin resistance and cigarette smoking. Lancet 1992; 339: 1128-1130.

44 Zedler BK, Kinser R, Oey J, Nelson B, Roethig HJ, Walk RA et al. Biomarkers of exposure and potential harm in adult smokers of 3-7 mg tar yield (federal trade commission) cigarettes and in adult nonsmokers. Biomarkers 2006; 11: 201-220.

45 Nilsson P, Lungren H, Soderstrom M, Fagerström KO, NilssonEhle P. Effects of smoking cessation on insulin and cardiovascular risk factors - a controlled study of 4 months duration. J Intern Med 1996; 240: 189-194.

46 Fleg JL, Gerstenblith G, Zonderman AB, Becker LC, Weisfeldt ML, Costa Jr PT et al. Prevalence of and prognostic significance of exercise induced silent myocardial ischemia detected by thallium scintigraphy. Circulation 1990; 81: 428-436.

47 Whiteneck GG, Charlifue SW, Frankel HL, Fraser MH, Gardner BP, Gerhart KA et al. Mortality, morbidity, and psychosocial outcomes of persons spinal cord injured more than 20 years ago. Paraplegia 1992; 30: 617-630.

48 Bauman WA, Raza M, Spungen AM, Machac J. Cardiac stress testing with thallium-201 imaging reveals silent ischemia in individuals with paraplegia. Arch Phys Med Rehabil 1994; 75: 946-950.

49 Bauman WA, Raza M, Machac J. Tomograhic thallium201 myocardial perfusion imaging after intravenous dipyridamole in asymptomatic subjects with quadriplegia. Arch Phys Med Rehab 1993; I74: 740-744

50 Lee CS, Lu YH, Lee ST, Lin CC, Ding HJ. Evaluating the prevalence of silent coronary artery disease in asymptomatic patients with spinal cord injury. Int Heart J 2006; 47: 325-330.

51 Orakzai SH, Orakzai RH, Ahmadi N, Agrawal N, Bauman WA, Yee $\mathrm{F}$ et al. Measurement of coronary artery calcification by electron beam computerized tomography in persons with chronic spinal cord injury: evidence for increased atherosclerotic burden. Spinal Cord 2007; 45: 775-779.

52 Bauman WA, Spungen AM. Risk assessment for coronary heart disease in a veteran population with spinal cord injury. Top Spinal Cord Inj Rehab 2007; 12: 35-53.

53 Castelli WP. Epidemiology of coronary heart disease: the Framingham study. Am J Med 1984; 76: 4-12.

54 Jarvinen HY, Koivisto VA. Effects of body composition on insulin sensitivity. Diabetes 1983; 32: 965-968.

55 Grimm DR, Almenoff PL, Bauman WA, DeMeersman RE. Baroreceptor sensitivity response to phase IV of the valsalva maneuver in spinal cord injury. Clin Auton Res 1998; 8: 111-118.

56 Kshirsagar AV, Carpenter M, Bang H, Wyatt SB, Colindres RE. Blood pressure usually considered normal is associated with an elevated risk of cardiovascular disease. Amer J Med 2006; 119: 133-141.

57 World Health Organization. Definition, Diagnosis and Classification of Diabetes Mellitus and its Complications: Report of a WHO Consultation. Part I: Diagnosis and Classification of Diabetes Mellitus. World Health Organization: Geneva, Switzerland, 1999 Available at: http://whqlidoc.who.int/hq/1999/ WHO_NCD_NCS_99.2pdf.

58 Einhorn D, Reaven GM, Cobin RH, Ford E, Ganda OP, Handelsman $\mathrm{Y}$ et al. American College of Enocrinology position statement on the insulin resistance syndrome. Endocr Pract 2003; 9: 237-252.

59 Joint statement from the American Diabetes Association and the European Association for the Study of Diabetes. The metabolic syndrome: time for a critical appraisal. Diabetes Care 2005; 28: 2289-2304. 